\title{
PHONOCARDIOGRAMS OF AURICULAR MURMURS FROM A CASE WITH MITRAL STENOSIS AND HEART BLOCK
}

\author{
BY \\ G. NYLIN ẢND G. BIÖRCK \\ From the Second Medical Department, Sabbatsbergs Sjukhus, Stockholm
}

Received August 15, 1946

It is well known that an auricular sound can sometimes be recognized by means of the stethoscope or phonocardiogram. In some instances it can be shown that the so-called first heart sound consists of a fusion of an auricular sound with a ventricular sound, and this may be evident in cases with prolongation of the P-R interval. This, however, is generally not easily recognized; otherwise there should be a presystolic sound or a double first heart sound in all cases of partial $\mathrm{A}-\mathrm{V}$ block.

In their monograph, Orias and Braun-Menendez (1939) state that three different acoustic phenomena contribute to the auricular first heart sound, namely-and in the following ordervibrations in the contracting auricles, the dilatation of the ventricles during their filling with blood, and vibrations in the mitral and tricuspid valves at the closure of the corresponding orifices at the end of the auricular systole. The first mentioned can only be studied from the œsophagus; the other two from the præcordium also.

It is stressed by different authors (Orias and Braun-Menendez, 1939; Bramwell, 1935; and Cossio and Fongi, 1936) that the auricular first heart sound will be increased during conditions, when the blood stream through the auriculo-ventricular orifices is increased or hastened (thyrotoxicosis, hypertension, and mitral stenosis with left auricular hypertrophy). It is also easy to understand that the rigidity of the valves in mitral stenosis might change the auricular sound to a murmur. If the statement of Levine (1941) is true, that seven-eighths of the blood stream from auricles to ventricles passes the orifice only on account of pressureequalization, whereas the last eighth is caused by auricular contraction, it will be clear that only the presystolic murmur in mitral stenosis is caused by auricular systole. This is also evident from the fact that the presystolic part of the diastolic murmur disappears when auricular fibrillation starts and there is no regular auricular systole.

We have recently studied a case of mitral stenosis with complete heart block, where the auricular murmur is very beautifully demonstrated on the phonocardiogram. As such cases are rare, according to Lewis (1944), and also from our own experiences, it might be of interest to report one instance. The physical and phonocardiographic quality of the sound places it in the class of murmurs.

\section{CASE REPORT}

A woman, 49 years old, whose mother and grandfather and uncle had organic heart disease, had diphtheria in childhood and acute rheumatic fever at the age of 18 . At the age of 25 dyspnœa and irregular heart action developed and the diagnosis of organic heart disease was made. She had a second attack of rheumatic fever four years later, after which there was increasing breathlessness, nocturia, pain in the chest, and irregular heart action.

The examination at the Sabbatsberg's hospital in 1943 revealed slight pre-tibial œdema and 
dyspnœa on action. Over the whole heart systolic and diastolic murmurs with their maxima over the heart base were heard. The rhythm seemed to be regular with some few premature beats. The blood pressure was 175/110. X-ray of the heart was normal, the size being 415 c.c. per square metre body surface. The cardiogram revealed a partial A-V block, which could not be influenced by atropine, alternating with complete heart block. The degree of the block seemed to be related to the course of the subjective symptoms.

At a fresh examination in 1945 there was, besides the above-mentioned murmurs, a peculiar, changing, possibly presystolic murmur over the apex, which made the occurrence of an auricular murmur suggestive. There was now complete heart block and right axis deviation in the cardiogram, as compared with normal axis in 1943.

Phonocardiograms (Fig. 1) confirmed this origin of the new murmur. In all frequenciesespecially the lower ones-there was besides the harsh systolic murmur over the apex, a murmur that was constantly related to the auricular activity ( $P$ wave). When the auricular systole appeared on its " normal" place in the chain of events, the auricular murmurs caused a typical presystolic murmur. Otherwise it was atypically located in the heart cycle. When
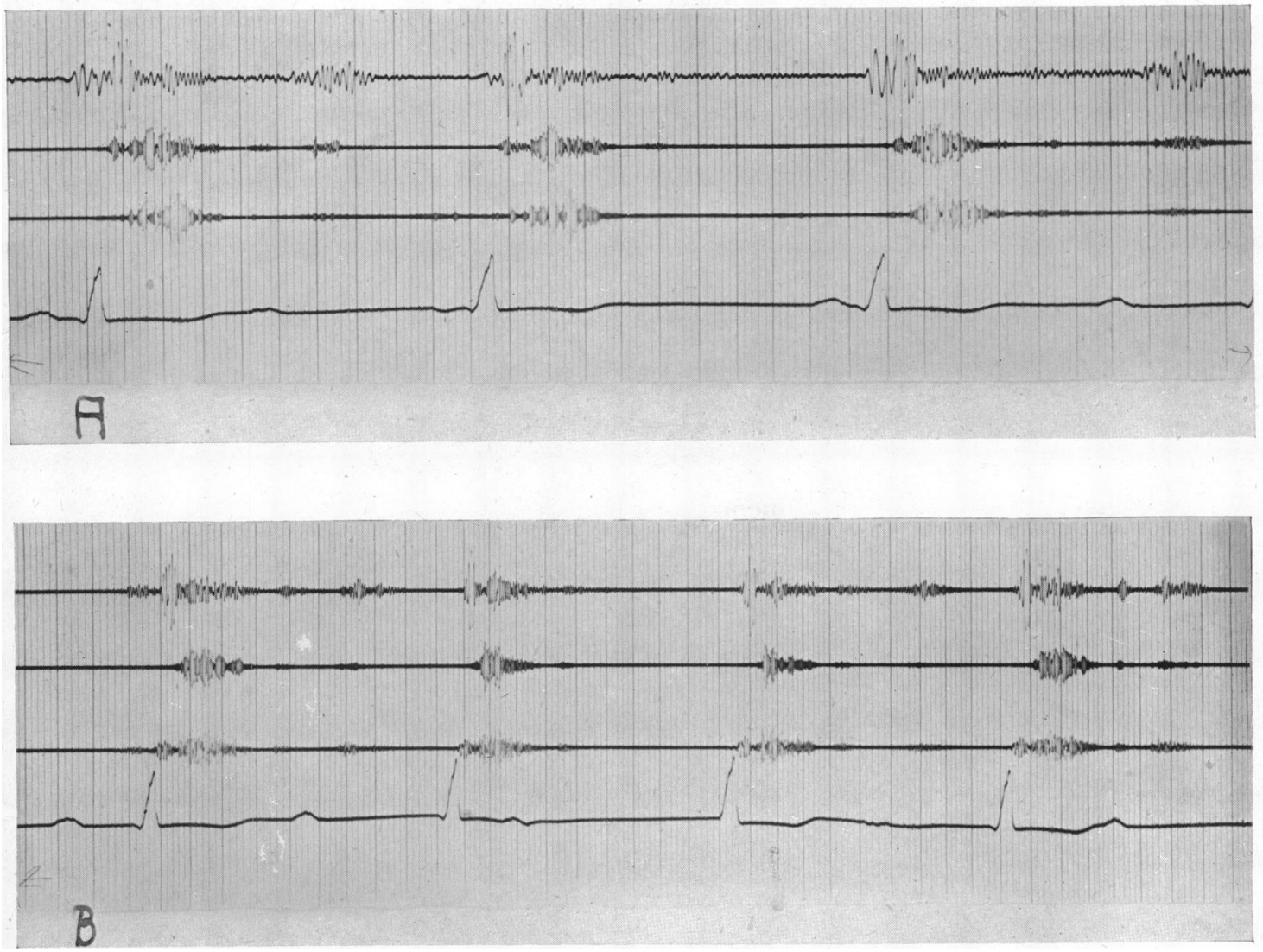

FIG. 1.-Calibrated phonocardiograms of the case described. (A) The upper three lines show the phonocardiograms with frequencies $15-100,170-290$, and 400-850 cycles, and the lowest line the electrocardiogram. (B) The upper three lines show the phonocardiograms with frequencies 80-180, 260-520, and 15-850 cycles, and the lowest line the electrocardiogram. In each instance the auricular contraction ( $P$ wave) is accompanied by the specific auricular murmur, independent of any relationship to the ventricular activity.

C 
it occurred independently it was evident that the murmur was not of the crescendo type, as has often been alleged. This is, as White (1944) has pointed out, an illusion caused by the close relationship between the presystolic murmur and the first heart sound, in which it is finally absorbed. In the case presented the auricular murmur was recorded on the phonocardiogram $0 \cdot 16 \mathrm{sec}$. after the beginning of the $P$ wave, which approximately corresponds to the findings of Orias and Braun-Menendez (1939). The duration was 0.14-0.16 seconds.

\section{SUMMARY}

A case of rheumatic heart disease with aortic stenosis and regurgitation and mitral stenosis is reported, where the existence of a complete heart block clearly demonstrates the auricular origin of the presystolic murmur in mitral stenosis.

\section{REFERENCES}

Bramwell, C. (1935). Quart. J. Med., 4, 139.

Bramwell, C., and King, J. T. (1942). The Principle and Practice of Cardiology, Lcndon.

Cossio, P., and Fongi, E. G. (1936). Amer. Heart J., 11, 723.

Levine, S. A. (1941). Clinical Heart Disease, Pniladelphia.

Lewis, T. (1944). Diseases of the Heart, Lond on.

Orias, O., and Braun-Menendez, E. (1939). The Heart Sounds in Normal and Pathological Conditions, London.

White, P. D. (1944). Heart Disease, New York. 